\title{
ПЕДАГОГИКА
}

\section{Метододогия образования}

\section{УДК 378.2}

\section{Дидактическое наследие А.А. Вербицкого и современность: к 80-летию со дня рождения}

\section{Didactic legacy of A.A. Verbitsky and the present: to the 80th anniversary of his birth}

\section{Ибрагимов Г.И., Казанский федеральный университет, guseinibragimov@yandex.ru}

\author{
Ibragimov G., Kazan Federal University, guseinibragimov@yandex.ru
}

\author{
DOI: 10.51379/KPJ.2021.148.4.001
}

\begin{abstract}
Ключевые слова: Вербицкий, контекстное обучение, контекстное образование, активное обучение, формы и методы активного обучения, дидактика высшей школь.
\end{abstract}

Keywords: Verbitsky, contextual learning, contextual education, active learning, forms and methods of active learning, didactics of higher education.

Аннотация. В статье раскрываются роль и место А.А. Вербиџкого в дидактике высшей школьл. Показано, что разработанная Вербицким теория контекстного образования оставалась востребованной педагогической наукой и практикой высшей школь в силу того, что она: во-первых, отвечает потребностям личности в самореализации в образовательной и профессиональной деятельности; во-вторых, потребностям общества в активных, инициативных, творческих и высоконравственных граждан; в-третьих, отличается глубокой психолого-педагогической обоснованностью основных положений, практико-ориентированностью, технологичностью и гибкостью, позволяющими ей вбирать все инновационное и таким образом адаптивно отвечать возникающим вызовам. Дается оченка личности Вербицкого как выдающегося ученого-педагога, отличаюшегося умением откликаться на то, что нужно именно сегодня, и одновременно заглядывать вперед, в будущее образования и педагогической науки.

Abstract. The article reveals the role and place of A.A. Verbitsky in the didactics of higher education. It is shown that the theory of contextual education developed by Verbitsky remained in demand in pedagogical science and practice of higher education due to the fact that it: firstly, meets the needs of an individual for self-realization in educational and professional activities; secondly, the needs of society for active, proactive, creative and highly moral citizens; thirdly, it is distinguished by a deep psychological and pedagogical substantiation of the main provisions, practice-orientedness, manufacturability and flexibility, allowing it to absorb everything that is innovative and thus adaptively respond to emerging challenges. An assessment of the personality of Verbitsky is given as an outstanding scientist-teacher, distinguished by the ability to respond to what is needed today, and at the same time to look ahead into the future of education and pedagogical science.

Введение. В начале 2021 года, незадолго до своего 80-летия, не стало академика РАО, доктора педагогических наук, профессора Андрея Александровича Вербицкого. А.А. Вербицкий это целое явление в дидактике высшей школы, вклад которого в педагогическую науку трудно переоценить. Впервые я познакомился с ним заочно в 1991 году, когда, будучи докторантом НИИ профтехпедагогики АПН СССР, купил в одном из книжных магазинов г. Казани только что опубликованную в издательстве «Высшая школа» его книгу «Активное обучение в высшей школе: контекстный подход» [1]. Эта работа очень быстро приобрела широкую известность, она продолжает оставаться актуальной и сегодня.

Здесь надо отметить, что публикация монографии в центральном педагогическом издательстве в те годы сама по себе было 
заметным и в то же время довольно сложным явлением. В отличие от сегодняшнего дня, когда практически любой желающий может опубликовать свою монографию в любом издательстве (были бы деньги). Последнее объяснялось тем, что рукопись должна была пройти очень непростую процедуру экспертной оценки на каждом этапе ее подготовки и представления. Серьезная и достаточно объективная экспертная оценка гарантировала качество опубликованной работы. Тем не менее, далеко не каждая опубликованная монография вносила заметный вклад в развитие теории и практики образования.

Работа А.А. Вербицкого как раз относилась к разряду тех, которые оказали существенное влияние на развитие теории и практики обучения в высшей школе. В этой связи отмечу еще один важный момент. Дело в том, что в 90-е годы в отечественной дидактике работала целая плеяда выдающихся ученых, имена которых были известны каждому, кто работал в системе образования - Ю.К. Бабанский, С.Я. Батышев, В.И. Загвязинский, В.В. Краевский В.С. Леднев, И.Я Лернер, М.И. Махмутов, В.Г. Разумовский и другие. В этом созвездии ярких имен очень легко было затеряться и пройти незамеченным. Но с Вербицким этого не случилось, как раз наоборот - c момента опубликования данной работы популярность автора и его идей только росли с каждым годом. О значении теории контекстного обучения в развитии современного образования говорит тот факт, что ссылки на работы А.А. Вербицкого по вопросам контекстного обучения в современной педагогической литературе встречаются даже чаще, чем в 90-х годах прошлого века. В чем же дело? Почему идеи Вербицкого оставались востребованными в течение всех последних трех десятилетий?

Об основных факторах, обусловливающчих востребованность разработанной А.А. Вербицким теории контекстного обучения. На мой взгляд, можно выделить три группы факторов, в том числе: социальноэкономический; научно-педагогический и личностный.

Если говорить о сочиально-экономическом факторе, то надо отметить, что в начале 90-х годов прошлого века произошла смена основ экономического устройства общества экономика социализма рухнула и на смену пришла экономика капитализма, в основе которой - частная собственность. Новый экономический уклад потребовал человека активного, инициативного, деятельного, адаптивного и т.п. Соответственно этому стала перестраиваться система образования на всех уровнях (школьное, СПО, ВПО, ДПО) его функционирования и развития. Парадигма изменения требований к образованию - переход от информационного, объяснительно-иллюстративного обучения к активному обучению, к формированию у выпускника свойств активной личности. Можно сказать, обобщая, что обществом и экономикой был востребован тип личности с активной позицией. Именно на это и была направлена концепция контекстного обучения, которая в силу этого оказалась общественно востребованной.

Теперь о научно-педагогическом факторе. Основная заслуга А.А. Вербицкого в том, что он акцентировал внимание на имевшем место противоречии между требованиями профессиональной деятельности к выпускнику, сводящимися к наличию у него умений и навыков решать профессиональные задачи разного уровня сложности и трудности, с одной стороны; и организацией образовательной деятельности обучающегося, ориентированной на формирование системы предметных знаний и умений - с другой. Разрешение этого противоречия требовало новых подходов к организации образовательного процесса, и А.А. Вербицкий нашел выход: он интегрировал две категории - активное обучение и контекстный подход в результате чего родилась концепция контекстного обучения. В чем ее особенности?

Они убедительно прописаны в его работах [13 и др.]. Поэтому, не останавливаясь на этом подробно, позволю себе акцентировать внимание на некоторых моментах.

Первое. Контекстный подход предполагает такую организацию обучения, которое бы осуществлялось с учетом особенностей будущей профессиональной деятельности. Но к тому времени в педагогике уже был достаточно глубоко проработан принцип профессиональной направленности обучения (М.И. Махмутов, С.Я. Батышев и др.), согласно которому в профессиональной школе образовательный процесс должен строиться с учетом требований будущей профессиональной деятельности. В этом плане существовали тщательно проработанные требования к проектированию содержания обучения, отбору и реализации методов, форм и средств обучения. Причем эти вопросы прорабатывались на методологическом, теоретическом и методическом уровнях исследования. В этой связи возникал вопрос - чем же отличается то, что предлагал и обосновывал А.А. Вербицкий?

Этот вопрос возникал и у меня в ходе ознакомления с данной концепцией. Больше того, 
первоначально у меня создавалось впечатление, что речь идет о реализации принципа профессиональной направленности обучения в высшей школе, только с использованием несколько другой терминологии. Но вскоре мне стало ясно, в чем заключается суть концепции А.А. Вербицкого.

Все дело в том, что, говоря о контексте, А.А. Вербицкий имел в виду не только предметносодержательный, но и социальный, а впоследствии и нравственно-этический контексты профессиональной деятельности специалиста. Именно интеграция содержательного и социального контекстов будущей профессиональной деятельности отличало подход Вербицкого. Справедливости ради следует отметить, что сама эта идея об интеграции не была новой - о ней немало писали и другие исследователи. Вклад Вербицкого в дидактику высшей школы состоял в том, что он предложил конкретную технологию подготовки будущего специалиста к выполнению социальнопрофессиональных функций. Эта технология предполагала такую организацию образовательной деятельности, в соответствии с которой студент последовательно вовлекался к контекст профессиональной деятельности через специально разработанную систему форм организации обучения: от академических к квазипрофессиональным и далее к учебнопрофессиональным формам организации образовательной деятельности.

Второе. Вербицкий обосновал восемь приниипов контекстного обучения (педагогического обеспечения личностного включения обучающегося в образовательную деятельность; единства обучения и воспитания личности обучающегося в одном потоке его образовательной деятельности; адекватности форм организации образовательной деятельности обучающихся целям и содержанию образования; педагогически обоснованного сочетания новых, в том числе цифровых, и традиционных педагогических технологий и др.), в числе которых мы бы вылелили принциипь последовательного моделирования в образовательной деятельности школьников, студентов, слушателей целостного содержания, форм и условий предстоящей им практической деятельности; проблемности содержания обучения и процесса его развертывания в образовательном процессе; ведущей роли совместной деятельности, межличностного взаимодействия и диалогического общения субъектов образовательного процесса обучающих и обучающихся.
Tретье. В контекстном образовании моделируется динамически сменяющая друг друга последовательность трёх базовьх моделей образовательной деятельности: академического типа, квазипрофессиональной и учебнопрофессиональной и множество переходных от одной к другой. Три базовые формы деятельности обучающегося, в процессе реализации которых осуществляется переход от одной формы к другой, реализуются посредством соответствующих образовательных моделей: семиотической, имитационной и социальной.

Семиотическая образовательная модель обеспечивает индивидуальное усвоение содержания вербальной или письменной информации в процессе традиционной, затем проблемной лекции, лекции вдвоем и др., решения учебных задач, выполнения заданий и др., превращающие эту информацию в знания. Ведущей единицей работы обучающегося выступает речевое действие.

Имитационная образовательная модель направлена на развитие у обучающихся практических умений по использованию сформированного посредством семиотической модели знания. Для этого предполагается моделирование в образовательном процессе ситуаций профессиональной деятельности посредством включения в учебный процесс решения ситуационных задач и проблем, метода проектов, анализа реальных ситуаций (кейсстади), мозгового штурма и др. Основной единицей образовательной деятельности обучающегося является предметное действие.

Сочиальная образовательная модель ориентирована на развитие социальных и морально-нравственных компетенций обучающегося. С этой целью воссоздаются профессиональные и исследовательские ситуации совместной деятельности, диалогического общения педагогов и обучающихся как субъектов образовательной деятельности посредством проектирования и реализации ролевой, деловой или иной игры, подготовки курсовой работы, в ходе разных видов практики, в процессе подготовки и защиты выпускной квалификационной работы и др. В процессе реализации этой модели единицей работы обучающегося выступает поступок.

Четвертое. Место А.А. Вербицкого в дидактике определяется и тем, что в сложные годы рыночных преобразований, когда ушли на задний план вопросы воспитания, он актуализировал проблему единства обучения $u$ воспитания. Особенно в последние годы (начиная с 2010 г.) он много об этом писал и выступал на 
научно-практических мероприятиях разного уровня. Концептуальные идеи о воспитании им были изложены в статье, опубликованной в журнале «Педагогика» [4]. Идея о единстве обучения и воспитания привела его к выводу о том, что надо говорить о контекстном образовании, и это можно рассматривать как развитие концепции контекстного обучения.

Надо отметить такую важнейшую черту Вербицкого, как умение откликаться на самые актуальные вызовы времени. Причем интересно, что он реагировал на эти вызовы так, чтобы найти место в решении актуальных проблем своей теории контекстного обучения. Так было, например, с компетентностным подходом. Задолго до того, как его нормативно внедрили в систему высшего образования (с 2013 года, после принятия Закона «Об образовании в РФ»), Вербицкий писал о компетентностном подходе. Он обосновывал мысль о том, что его реализация требует соответствующей теории и технологии и в качестве таковой предлагал вполне убедительно использовать концепцию контекстного обучения. И надо сказать, что его предложения были восприняты и по крайней мере частично реализованы в требованиях ФГОС ВО второго и третьего поколения. Это, в частности, выразилось в том, что нормативно было закреплено требование об использовании активных форм и методов обучения в процессе подготовки бакалавров и магистров в объеме не менее 20\% учебного времени. В требованиях ФГОС ВО подчеркивалось, что «реализация компетентностного подхода должна предусматривать широкое использование в учебном процессе активных и интерактивных форм проведения занятий (компьютерных симуляций, деловых и ролевых игр, разбора конкретных ситуаций, психологических и иных тренингов) в сочетании с аудиторной работой с целью формирования и развития профессиональных навыков обучающихся ...» [5].

Каждая форма выполняет определенную доминирующую функцию по формированию у обучающихся той или иной компетенции. Так, компьютерные симуляции ориентируют на формирование профессиональных навыков, связанных с использованием компьютера для моделирования различных явлений и процессов, встречающихся в жизни и профессиональной деятельности. Деловые и ролевые игры решают, прежде всего, задачу формирования профессионально значимых навыков взаимодействия с людьми, выполнения различных ролей и т.п. Например, такая общекультурная компетенция (ОК-5), как «готов к взаимодействию с коллегами, к работе в коллективе», объективно требует использования игровых форм проведения занятий с включением в процесс всех обучающихся. Разбор конкретных ситуаций направлен на формирование умений анализировать реальную ситуацию, возникающую в профессиональной и иной деятельности, находить решения в ситуациях неопределенности и т.П. Психологические и другие тренинги решают задачи формирования у обучающихся способности анализировать социально и личностно значимые проблемы, ставить цели и выбирать пути их достижения и Т.Д.

Важно обратить внимание и на фиксировании требования о том, что удельный вес занятий в интерактивной форме должен составлять не менее $20 \%$ аудиторных занятий, а в структуре применяемых форм организации обучения удельный вес лекционных занятий был ограничен (не более $40 \%$ аудиторных занятий). Это означает переход на доминирование практикоориентированного характера обучения.

Здесь же отражена идея Вербицкого о том, что подготовка выпускников для работы в современных условиях развития общества в целом и рынка труда в частности, должна интегрировать не только предметные знания, умения и навыки, но и развивать у них навыки взаимодействия с социальным и профессиональным окружением. Для этого в требованиях ФГОС ВО предусмотрено обязательное проведение мастер-классов экспертов и специалистов, встреч с представителями компаний (отечественных и зарубежных), государственных и общественных организаций. Эти формы ответственны за формирование профессиональных и социальных компетенций у обучающихся, накопление ими опыта соответствующей деятельности.

Вычлененные особенности форм, методов и средств компетентностно-ориентированного обучения создают в вузе образовательную среду, обеспечивающую сочетание фундаментальной и прикладной подготовки обучающихся, моделирование в образовательном процессе профессиональной и социальной реальности, способствующей погружению обучающихся в контекст будущей профессиональной и социальной деятельности.

В последние годы Андрей Александрович уделял достаточно много внимания проблемам цุифровизации образования. В одной из последних статей на эту тему он затронул несколько важных вопросов и один из основных - обеспечивает ли 
совокупность качеств, приобретённых человеком в процессе цифрового обучения, эффективное и безопасное выполнение различных социальных и профессиональных функций?

Рассуждая над этим вопросом, Вербицкий останавливается на методологических проблемах: что есть циифровое обучение и цицрровое образование? каковы риски циифрового обучения?

Рассматривая понятийно

терминологический аппарат он писал, что использование термина «циифровое обучение», как и связанного с ним понятия «цицрровая дидактика», т.е. теория цифрового обучения, не вызывают сомнения, поскольку в них речь идёт о закономерностях, принципах и механизмах усвоения обучающимися предметных знаний, умений, навыков, компетенций, в том числе с использованием компьютера.

А вот термин «циифровое образование», по его мнению, неправомерен, поскольку слово «образование» несёт в себе три разных смысла в зависимости от контекста его употребления в речи. Первый смысл - это образовательный ценз конкретного человека, который в ответ на вопрос, какое у него образование, отвечает: общее среднее, профессиональное или высшее. Второй смысл - система образования как совокупность образовательных программ, их реализующих образовательных организаций и система управления ими. Третий смысл - процесс образования, состоящий из обучения и воспитания в их единстве, как две стороны одной «медали».

Исходя из этих различий, он считал правомерным использовать только терминь «ицифровая система образования» и «циифровое обучение», поскольку компьютер «не занимается» воспитанием обучающиихся.

Говоря о рисках цифровизации для образования, Вербицкий в числе целого их ряда выделял следующие:

1. В циифровом обучении речь не идет о воспитании, тогда как вместе с обучением они должны составлять две сторонь одной «медали» - образования. Воспитание - это морально-нравственная категория. Нравственность - качество личности, которое предполагает при своём формировании эмоционально-ценностное отношение к содержанию ситуащий диалогического общения и взаимодействия включенных в них людей, onblm чувственного (положительного или отрицательного) переживания человеком отношений между людьми, возникающих в этих ситуациях. Источником таких переживаний и отношений, носителем морали и нравственности может быть только человек - родитель, педагог, любой представитель социума, но не как угодно мощное цифровое устройство.

2. В циифровом обучении доведён до абсурда известный принции индивидуализащуии. Принциип индивидуализации, понимаемый как оставление каждого обучающегося наедине с компьютерной обучающей программой: а) ещё больше усиливает отрыв обучения от воспитания; б) лишает обучающегося возможности полноценного психического развития, как это происходит в так называемом «чиповом обучении».

Если пойти по пути тотальной индивидуализачии обучения с помощуью персональных компьютеров, можно прийти к тому, что будет упущена сама возможность формирования творческого мышиения, которое по своему происхождению диалогично. Есть и другая опасность: свёртывание социальных контактов, сокращение практики социального взаимодействия и общения, что приводит $к$ индивидуализму и одиночеству.

Однако, вычленяя болевые точки цүифровизачии, Вербицкий подчеркивал, что это не означает, что не следует использовать цифровое обучение, как раз наоборот. Но важно при этом «не пересолить», найти психологически, физиологически, педагогически и методически обоснованный баланс между использованием возможностей компьютера и жсиьм диалогическим общением субъектов образовательного проиесса - педагога $u$ обучающихся [6].

Сохраняя верность своей концепции Вербицкий сделал вывод о том, что в качестве научной основы, $к$ которой может быть «привязана» цицфровизачия обучения, в наибольшей мере способна стать психологопедагогическая теория контекстного образования, в проиессе которого создаются необъятные возможности использования компьютера в качестве мочного и необходимого средства обеспечения его содержания и прочесса без редукции образовывающегося школьника, студента или слушателя ФПК к цифровому устройству, к мозгу, в котором конечно происходит что-то, получившее название «переработка информации [6].

Если говорить о личностном факторе, то надо отметить, что личность А.А. Вербицкого неординарная. Он всегда занимал активную жизненную позицию, неустанно занимался общественной деятельностью. У него была редкая способность - видеть детали под большим углом, что особенно ярко проявлялось в процессе анализа диссертационных исследований и других 
научных материалов. Андрея Александровича характеризовали убедительность и принципиальность, умение откликаться на то, что нужно именно сегодня, и одновременно заглядывать вперед, в будущее образования и педагогической науки.

Поднимаясь до высоких теоретических обобщений, А.А. Вербицкий никогда не отрывался от практики, всегда знал ее потребности и перспективы развития. Он много выступал перед практиками - учителями, преподавателями профессиональной и высшей школы, всегда был открыт общению, умел излагать свои мысли очень четко, точно, простым и доступным языком, так что все было понятно как начинающим исследователям, так и состоявщимся ученым.

Заключение. Нам представляется, что в современной дидактике введенный и обоснованный А.А. Вербицким принцип контекстности, следует рассматривать как один из ведущих общепедагогических принципов обучения. А созданная им теория контекстного образования, впитавшая лучшие идеи и практический педагогический опыт второй половины двадцатого века, в современных условиях может явиться ключевой основой развития современного профессионального образования и дидактики высшей школы.

\section{Лumepamypa:}

1. Вербицкий А.А. Активное обучение в высшей школе: контекстный подход / А.А. Вербицкий. - М.: Высшая школа, 1991.

2. Вербицкий А.А., Калашников В.Г. Категория «контекст» в психологии и педагогике / А.А. Вербицкий, В.Г. Калашников. - М.: Логос, 2010.

3. Вербицкий А.А. Теория и технологии контекстного образования: Учебное пособие / А.А. Вербицкий. - М., МПГУ, 2017.

4. Вербицкий А.А. Воспитание в современной образовательной парадигме / А.А. Вербицкий // Педагогика. - 2016. - № 3. - С. 3-16.
5. Ибрагимов Г.И. Процесс обучения в высшей школе в условиях реализации ФГОС: болевые точки / Г.И. Ибрагимов // Alma-mater. - 2013. - № 8. - С. 6-14.

6. Вербицкий А.А. Цифровое обучение: проблемы, риски и перспективы [Электронный ресурс] / А.А. Вербицкий // Электронный научнопублицистический журнал "Ното Cyberus". - 2019. - № 1(6). - Режим доступа: http://journal.homocyberus.ru/Verbitskiy_AA_1_2019, свободный

\section{References:}

1. Verbitsky A.A. Active learning in higher school: contextual approach / A.A. Verbitsky. - M.: Higher school, 1991.

2. Verbitsky A.A., Kalashnikov V.G. Category "context" in psychology and pedagogy / A.A. Verbitsky, V.G. Kalashnikov. - M.: Logos, 2010.

3. Verbitsky A.A. Theory and technology of contextual education: Textbook / A.A. Verbitsky. - M., Moscow State Pedagogical University, 2017.

4. Verbitsky A.A. Education in the modern educational paradigm / A.A. Verbitsky // Pedagogy. - 2016. - № 3. - P. 3-16.

5. Ibragimov G.I. The process of teaching in a higher school in the context of the implementation of the Federal State Educational Standard: pain points / G.I. Ibragimov // Alma-mater. - 2013. - № 8. - S. 6-14.

6. Verbitsky A.A. Digital education: problems, risks and prospects [Electronic resource] / A.A. Verbitsky // Electronic scientific journal "Homo Cyberus". - 2019. - № 1(6). - Access mode: http://journal.homocyberus.ru/ Verbitskiy_AA_1_2019, free

13.00.01 - Общая педагогика, история педагогики и образования

\section{Сведения об авторе:}

Ибрагимов Гасангусейн Ибрагимович (г. Казань, Россия), член-корреспондент РАО, доктор педагогических наук, профессор, профессор кафедры педагогики высшей школы Института психологии и образования Казанского федерального университета, e-mail: guseinibragimov@yandex.ru 